\title{
Use of silver nanowires to determine thresholds for fibre length-dependent pulmonary inflammation and inhibition of macrophage migration in vitro
}

Anja Schinwald ${ }^{1}$, Tanya Chernova $^{2}$ and Ken Donaldson ${ }^{1 *}$

\begin{abstract}
Background: The objective of this study was to examine the threshold fibre length for the onset of pulmonary inflammation after aspiration exposure in mice to four different lengths of silver nanowires (AgNW). We further examined the effect of fibre length on macrophage locomotion in an in vitro wound healing assay. We hypothesised that exposure to longer fibres causes both increased inflammation and restricted mobility leading to impaired clearance of long fibres from the lower respiratory tract to the mucociliary escalator in vivo.

Methods: Nine week old female C57BL/6 strain mice were exposed to AgNW and controls via pharyngeal aspiration. The dose used in this study was equalised to fibre number and based on $50 \mathrm{\mu g} /$ mouse for $\mathrm{AgNW}_{14}$. To examine macrophage migration in vitro a wound healing assay was used. An artificial wound was created in a confluent layer of bone marrow derived macrophages by scraping with a pipette tip and the number of cells migrating into the wound was monitored microscopically. The dose was equalised for fibre number and based on $2.5 \mathrm{\mu g} / \mathrm{cm}^{2}$ for $\mathrm{AgNW}_{14}$.

Results: Aspiration of AgNW resulted in a length dependent inflammatory response in the lungs with threshold at a fibre length of $14 \mu \mathrm{m}$. Shorter fibres including 3, 5 and $10 \mu \mathrm{m}$ elicited no significant inflammation. Macrophage locomotion was also restricted in a length dependent manner whereby AgNW in the length of $\geq 5 \mu \mathrm{m}$ resulted in impaired motility in the wound closure assay.

Conclusion: We demonstrated a $14 \mu \mathrm{m}$ cut-off length for fibre-induced pulmonary inflammation after aspiration exposure and an in vitro threshold for inhibition of macrophage locomotion of $5 \mu \mathrm{m}$. We previously reported a threshold length of $5 \mu \mathrm{m}$ for fibre-induced pleural inflammation. This difference in pulmonary and pleural fibre- induced inflammation may be explained by differences in clearance mechanism of deposited fibres from the airspaces compared to the pleural space. Inhibition of macrophage migration at long fibre lengths could account for their well-documented long term retention in the lungs compared to short fibres. Knowledge of the threshold length for acute pulmonary inflammation contributes to hazard identification of nanofibres.
\end{abstract}

Keywords: Asbestos fibre, Silver nanofibres, Aspiration, Clearance, Migration

\footnotetext{
* Correspondence: ken.donaldson@ed.ac.uk

${ }^{1} \mathrm{MRC} /$ University of Edinburgh, Centre for Inflammation Research, Queen's Medical Research Institute, 47 Little France Crescent, Edinburgh EH16 4TJ, UK Full list of author information is available at the end of the article
} 


\section{Background}

The determinants of the pathogenicity of fibrous materials include fibre diameter, length and biopersistence which form the basis of the fibre pathogenicity paradigm (FPP) [1]. Studies on asbestos fibres, synthetic vitreous fibres and nanofibres have shown that they all may pose a significant health hazard when inhaled during their manufacture and/or use [2-5]. These various different fibrous materials possess considerable differences in their pathogenicity in keeping with the FPP [6]. It has been accepted for many years that fibre length plays a crucial role in the development of asbestos related diseases. For example Davis et al. performed a number of experiments investigating the pathogenicity of various length and compositions of asbestos fibres via the routes of inhalation and intraperitoneal injection [7,8]. The inhalation studies showed that fibres with a significant proportion $(\sim 11 \%)$ of fibres $>$ $10 \mu \mathrm{m}$ caused widespread pulmonary fibrosis and cancer whereas shorter fibres (less than $5 \mu \mathrm{m}$ ) and UICC amosite (intermediate length) caused less fibrosis or carcinogenesis. However, the UICC amosite fibres and long asbestos fibres had similar potency in causing mesothelioma whilst virtually no carcinogenicity was seen with short fibres [8]. This study showed for the first time a difference in the fibre lengths required for the induction of lung diseases and the lengths for peritoneal mesothelioma and by analogy pleural mesothelioma. However, the precise threshold lengths for both lung and peritoneal pathology after fibre exposure were unknown at the time. In a recent study we determined the threshold length for fibre-induced pathogenicity in the pleura [9] as being $5 \mu \mathrm{m}$, using distinct length classes of silver nanowires (AgNW). The aim of the current study was to determine the threshold length for fibre-induced lung inflammation by comparing the pulmonary inflammatory response to the same panel of different length classes of AgNW after their deposition in the airspaces of the lungs.

The normal lung clearance mechanisms provide a defence mechanism for removing fibre dose and yet selective retention of longer fibres is well-documented $[10,11]$. For the key fraction of fibres that deposit beyond the ciliated airways and are slowly cleared, macrophage are the central cells involved in phagocytosing and transporting the fibres to the foot of the mucociliary escalator for clearance. We therefore hypothesised that the uptake of long fibres impairs the ability of macrophages to migrate whilst short fibres do not, providing a mechanism for selective retention of long fibres. We addressed this hypothesis using the samples with different fibre length classes and assessed their effects on macrophage migration in an in vitro wound closure assay.

\section{Results}

Length dependent inflammatory response to AgNW in lung at $\mathbf{2 4}$ hour

The panel of AgNW used for pharyngeal aspiration is represented in Figure 1. The inflammatory response to the panel of AgNW and control fibres as assessed by the bronchoalveolar lavage fluid (BAL) profile was measured 24 hour post aspiration. An initial dose response series was performed with $\mathrm{AgNW}_{14}$ at a dose of 5, 10, 25 and
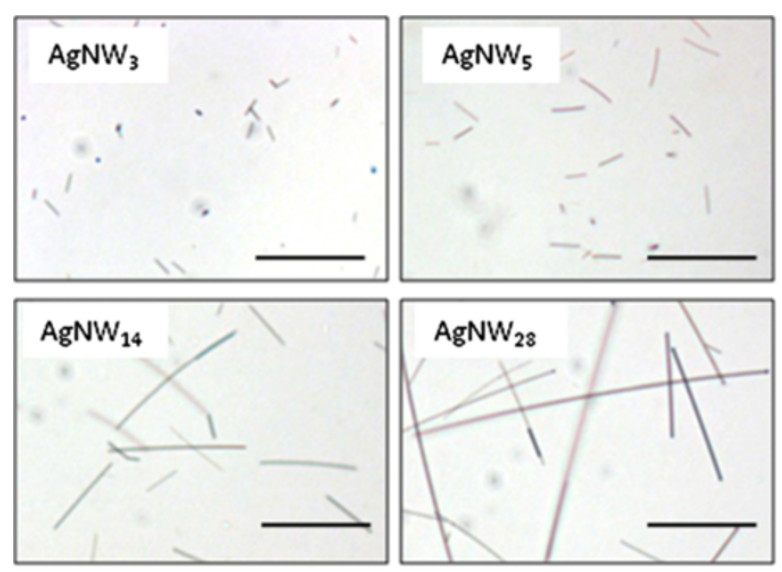

\begin{tabular}{|cccccc|}
\hline & $\mathrm{AgNW}_{3}$ & $\mathrm{AgNW}_{5}$ & $\mathrm{AgNW}_{10}$ & $\mathrm{AgNW}_{14}$ & $\mathrm{AgNW}_{28}$ \\
\hline Mean length $(\mu \mathrm{m})$ & 3 & 5 & 10 & 14 & 28 \\
\hline$\%$ fibre $\geq 5 \mu \mathrm{m}$ & 0 & 55 & 98 & 96 & 100 \\
\hline Diameter (nm, mean \pm s.e.m.) & $115 \pm 3$ & $118 \pm 3$ & $128 \pm 2$ & $121 \pm 3$ & $120 \pm 4$ \\
\hline
\end{tabular}

Figure 1 Characteristics of AgNW panel. Representative images of the AgNW (1 mg/ml) and their mean length ( $\mu$ m), percentage of fibre $\geq 5 \mu \mathrm{m}$ and average diameter $(\mathrm{nm})$. Scale bar: $10 \mu \mathrm{m}$.

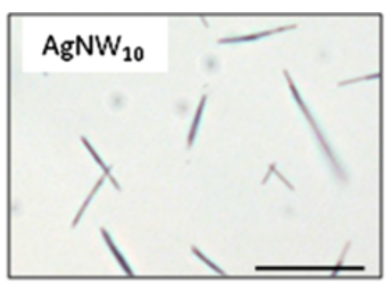

Scale bar: $10 \mu \mathrm{m}$ 
Table 1 Calculation for the mass adjustments for equalisation of fibre number in vivo

\begin{tabular}{lccc}
\hline Particle & $\begin{array}{l}\text { Calculation to equalise for } \\
\text { the same fibre number }\end{array}$ & $\begin{array}{l}\text { Dose } \\
(\boldsymbol{\mu g} / \text { mouse })\end{array}$ & $\begin{array}{l}\text { Total fibre } \\
\text { number }\end{array}$ \\
\hline SFA & Short fibre control & 10.7 & $50.48^{*} 10^{6}$ \\
\hline AgNW $_{\mathbf{3}}$ & $3 / 14 \times 50$ & 10.7 & $32.71 * 10^{6}$ \\
\hline AgNW $_{\mathbf{5}}$ & $5 / 14 \times 50$ & 17.9 & $31.19 * 10^{6}$ \\
\hline AgNW $_{\mathbf{1 0}}$ & $10 / 14 \times 50$ & 35.7 & $28.17 * 10^{6}$ \\
\hline AgNW $_{\mathbf{1 4}}$ & standard & 50.0 & $32.76 * 10^{6}$ \\
\hline LFA $^{*}$ & Long fibre control & 50.0 & $8.24^{*} 10^{6}$ \\
\hline
\end{tabular}

*LFA fibre counting 164,705 fibres/ $\mu \mathrm{g}$ on the basis of WHO counting criteria.

$50 \mu \mathrm{g} /$ mouse $(\mathrm{n}=2)$ and SFA and LFA at a dose of 10 and $50 \mu \mathrm{g} /$ mouse $(\mathrm{n}=2)$ (data not shown). The dose of $50 \mu \mathrm{g} /$ mouse was chosen since it gave a persistent inflammatory response with $\mathrm{AgNW}_{14}$ and LFA. The dose was adjusted so that each of the different treatments (Table 1) comprised the similar fibre number. No change in total bronchoalveolar cell number was measured after exposure to equal numbers of the different fibre lengths compared to vehicle control (Figure 2A). However the total number of granulocytes was significantly increased after exposure to $\mathrm{AgNW}_{14}$ (Figure 2B). A length dependent trend towards an increase in granulocyte number with $\mathrm{AgNW}_{5}$, $\mathrm{AgNW}_{10}$ and LFA was observed, although this was not significant (Figure 2B). $\mathrm{AgNW}_{3}$ and SFA produced no increase in granulocyte number compared to VC (Figure 2B).
The effect of length on inflammation was demonstrated by plotting AgNW length against inflammation and it is clear that the relationship is not linear and that there is a discernible step-increase in granulocyte recruitment at a length between 10 and $14 \mu \mathrm{m}$. (Figure 2C). Total amount of protein and increase in membrane permeability by the release of LDH was measured but showed no significant difference between the treatments (data not shown).

\section{Histological evaluation of lung sections following treatments}

The pathology of the lung exposed to the AgNW panel and controls were examined 24 hour after aspiration. The sections after exposure to VC, SFA and $\mathrm{AgNW}_{3}$ showed normal histology of bronchioles, respiratory bronchioles, alveolar ducts and alveoli (Figures 3A, B, D and Additional file 1: Figure S1). $\mathrm{AgNW}_{5}$ and $\mathrm{AgNW}_{10}$ produced minor granulomas and lymphocyte infiltrates and the majority of the lung histology appeared normal. $\mathrm{AgNW}_{14}$ and LFA caused more extensive granuloma and lymphocyte infiltrates which is consistent with the amount of total granulocytes from the lavage fluid (Figure 3E, F, and Additional file 1: Figure S1). Accumulations of nanowires inside alveolar macrophages were common (Figure 3E, F white arrow and Additional file 1: Figure S1). $\mathrm{AgNW}_{14}$ produced the strongest response with more granulomatous areas compared to shorter
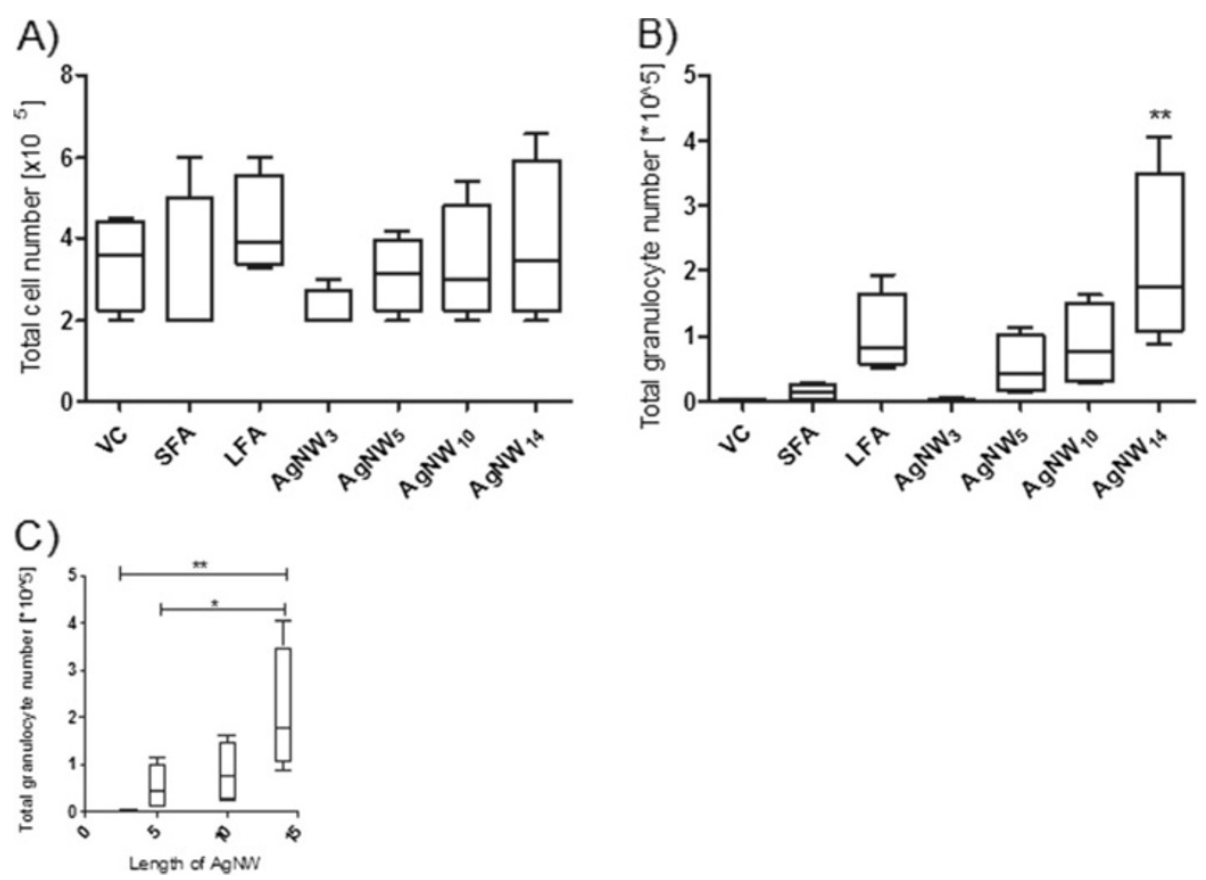

Figure 2 Length dependent inflammatory response to AgNW in the lungs at $\mathbf{2 4}$ hour. C57/Bl6 mice were exposed to AgNW and control panel by pharyngeal aspiration. At 24 hour post exposure the lungs were lavaged and total cell number $(\mathbf{A})$ and total granulocyte number (B) were measured. C) The acute inflammatory increase was plotted against length of AgNW. Significance indicated compares treatment groups to vehicle control (B) and within each treatment $(\mathbf{C}),{ }^{*}$ indicates $p<0.05$, ${ }^{* *}$ indicates $p<0.001$. Data represent mean \pm SEM of $n=4$ mice. 


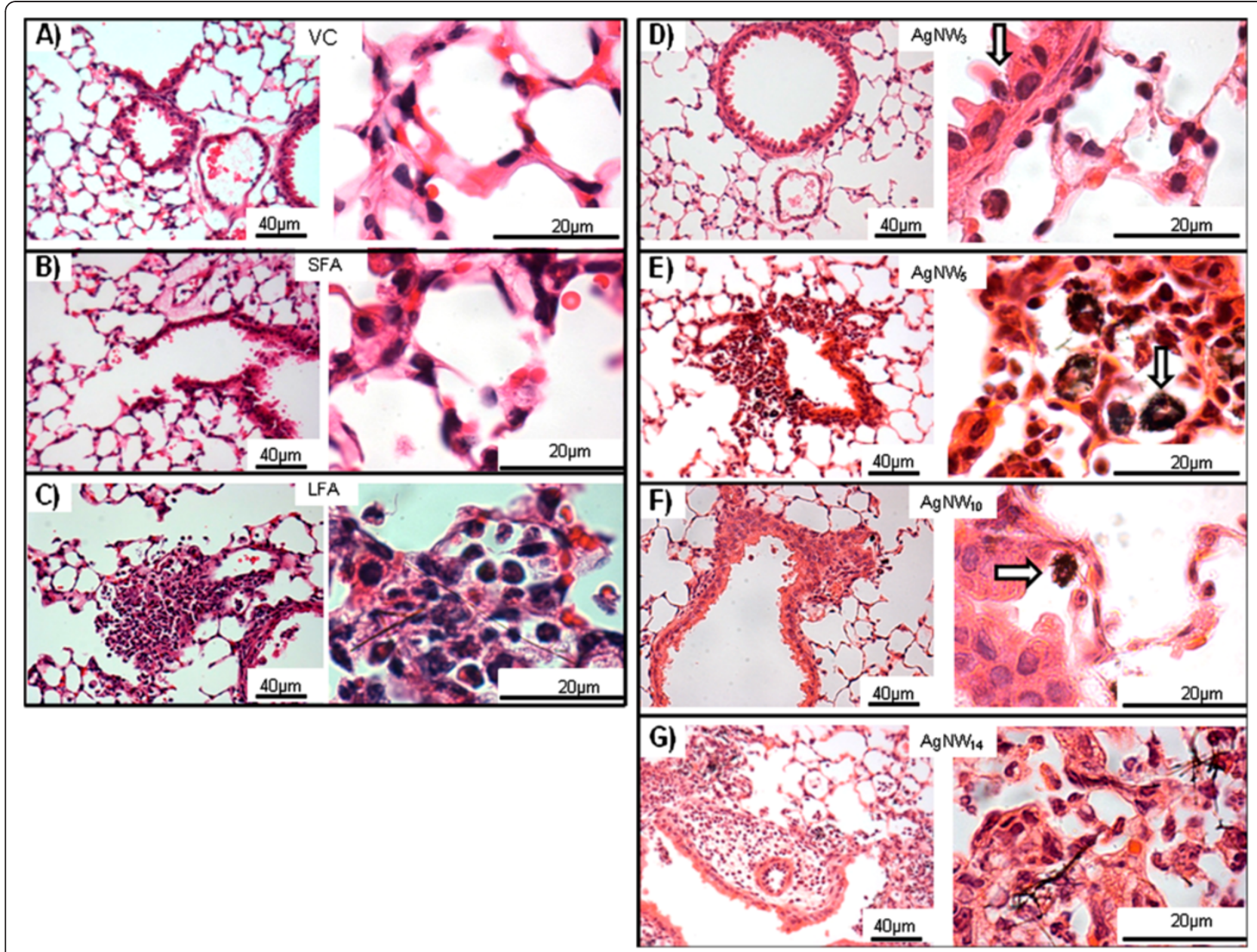

Figure 3 Lung histology 24 hour post aspiration to AgNW panel and controls. H\&E stained lung sections at lower (left) and higher (right) magnification show normal alveolar structure in the vehicle control (A), SFA (B) and $\mathrm{AgNW}_{3}$ (D) sections. Small accumulations of inflammatory cells were seen after $\mathrm{AgNW}_{5}(\mathbf{E})$ and $\mathrm{AgNW}_{10}(\mathbf{F})$ exposure whereas a greater amount of inflammatory cell infiltration in the alveoli, peribronchiolar and perivascular regionswere observed after LFA $(\mathbf{C})$ and $\operatorname{AgNW}_{14}(\mathbf{G})$. The white arrows are indicating the areas of fibre accumulation. Abbreviations: al, alveolus; br, bronchiole; v, blood vessel. Representative images are shown, similar results are obtained from 2 mice.

fibres however this was still minor compared to the extensive interstitial thickening and remodelling of the alveolar spaces after LFA treatment (Figure 3C, G, and Additional file 1: Figure S1). Frustrated phagocytosis, classified as incomplete uptake of fibres by cells [12], was observed with $\mathrm{AgNW}_{14}$ and LFA.

\section{Frustrated phagocytosis in alveolar macrophages}

The uptake of different length of AgNW by alveolar macrophages was evident in cytospin images of the broncho-alveolar lavage fluid (Figure 4). Shorter fibres including SFA, $\mathrm{AgNW}_{3}, \mathrm{AgNW}_{5}$ and $\mathrm{AgNW}_{10}$ could be completely phagocytosed by alveolar macrophages (Figure 4B, D, E) whereas LFA, and $\mathrm{AgNW}_{14}$ were undergoing frustrated phagocytosis indicated by the sharing of fibres between adjacent cells (Figure 4C, G). This is in agreement with frustrated phagocytosis observed in histological sections and the extent of inflammation seen in the lavage fluid showing that frustrated phagocytosis of nanowires correlates with increased inflammation.

Fibre-length dependent inhibition of locomotion in bone marrow derived macrophages

As shown in Figure 5A and Additional file 1: Figure S2, the untreated cells migrated into and repopulated wounds area within 30 hour. Similar wound closure was seen after treatment with silver nanoparticles $(\mathrm{AgP})$ and $\mathrm{AgNW}_{3}$ (Figure 5A). A slight decrease in the closure of the wound occurred during treatment with $\mathrm{AgNW}_{5}$ whilst BMMs treated with $\mathrm{AgNW}_{14}$ and $\mathrm{AgNW}_{28}$ (Figure 5B) demonstrate a substantial decrease in the ability to migrate into the wound compared to VC. The number of cells which 

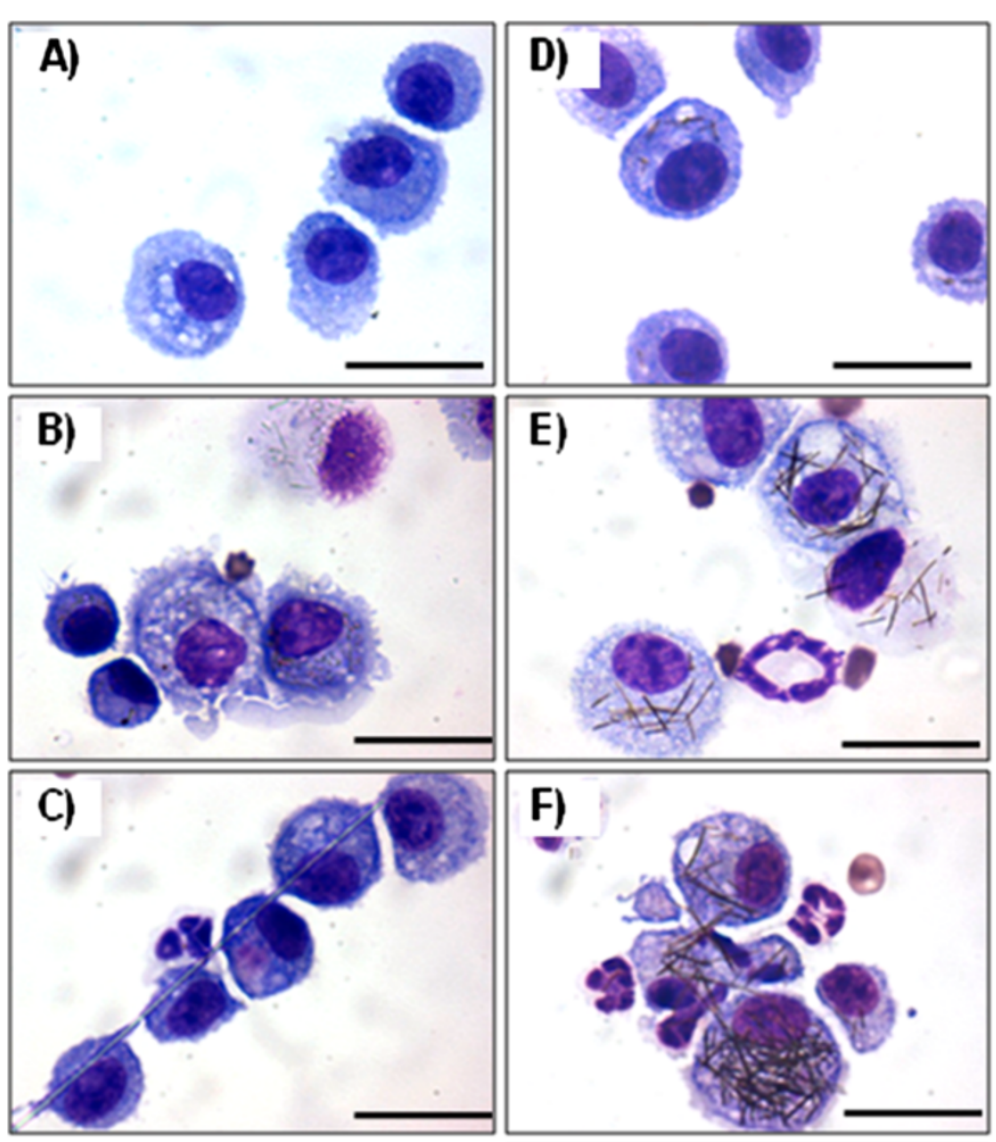

Scale bar: $20 \mu \mathrm{m}$

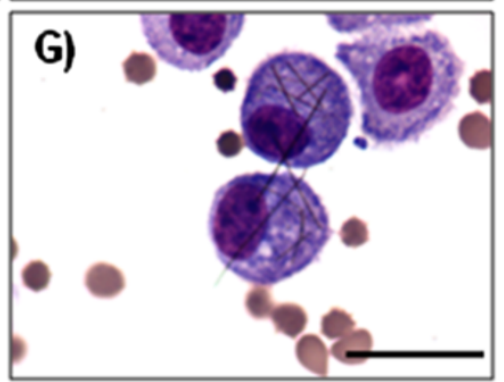

Figure 4 Uptake of AgNW and controls in alveolar macrophages. Cytospin images from the lavage fluid 24 hour post aspiration illustrates the complete uptake of shorter fibres including SFA (B), $\operatorname{AgNW}_{3}(\mathbf{D}), \mathrm{AgNW}_{5}(\mathbf{E})$ and $\mathrm{AgNW}_{10}(\mathbf{F})$ whereas LFA (C) and $\mathrm{AgNW}_{14}(\mathbf{G})$ lead to frustrated phagocytosis in alveolar macrophages. Scale bar $20 \mu \mathrm{m}$.

migrated into the wound were counted and expressed as percentage of migrated cells normalised to $\mathrm{VC}$ and this revealed that locomotion was significantly decreased with $\mathrm{AgNW}_{5}, \mathrm{AgNW}_{14}$ and $\mathrm{AgNW}_{28}$ (Figure 6A). Cytochalasin D, a positive control which causes impaired migration due to disruption of the actin filaments produced a decrease in locomotion comparable to $\mathrm{AgNW}_{14}$ (Figure 6A). Differences in the rate of metabolic activity or cell death could not account for the inability of macrophages to migrate into the wound as the treatment did not interfere with the metabolic activity measured via chemical reduction of Alamar Blue $^{\circledR}$ (Figure 6B) and had no effect on cell membrane integrity measured as the release of lactate dehydrogenase into cell supernatant (Figure 6C). Decrease in cell adhesion has been linked to a decrease in the ability of cell migration. Backscatter scanning electron microscopy (BSE) images confirm that treatment with AgNW did not impair the ability of cell adhesion and spreading (Figure 5A,B). To the contrary, extensive cell spreading is observed in cells treated with long fibres presumably a consequence of BMMs increasing the surface area involved in engulfing the fibres (Figure 5A, B). Using BSE, nanowires and nanoparticles phagocytosed by BMMs could be visualised underneath the membrane as indicated by the arrow (Figure 5A, B). 

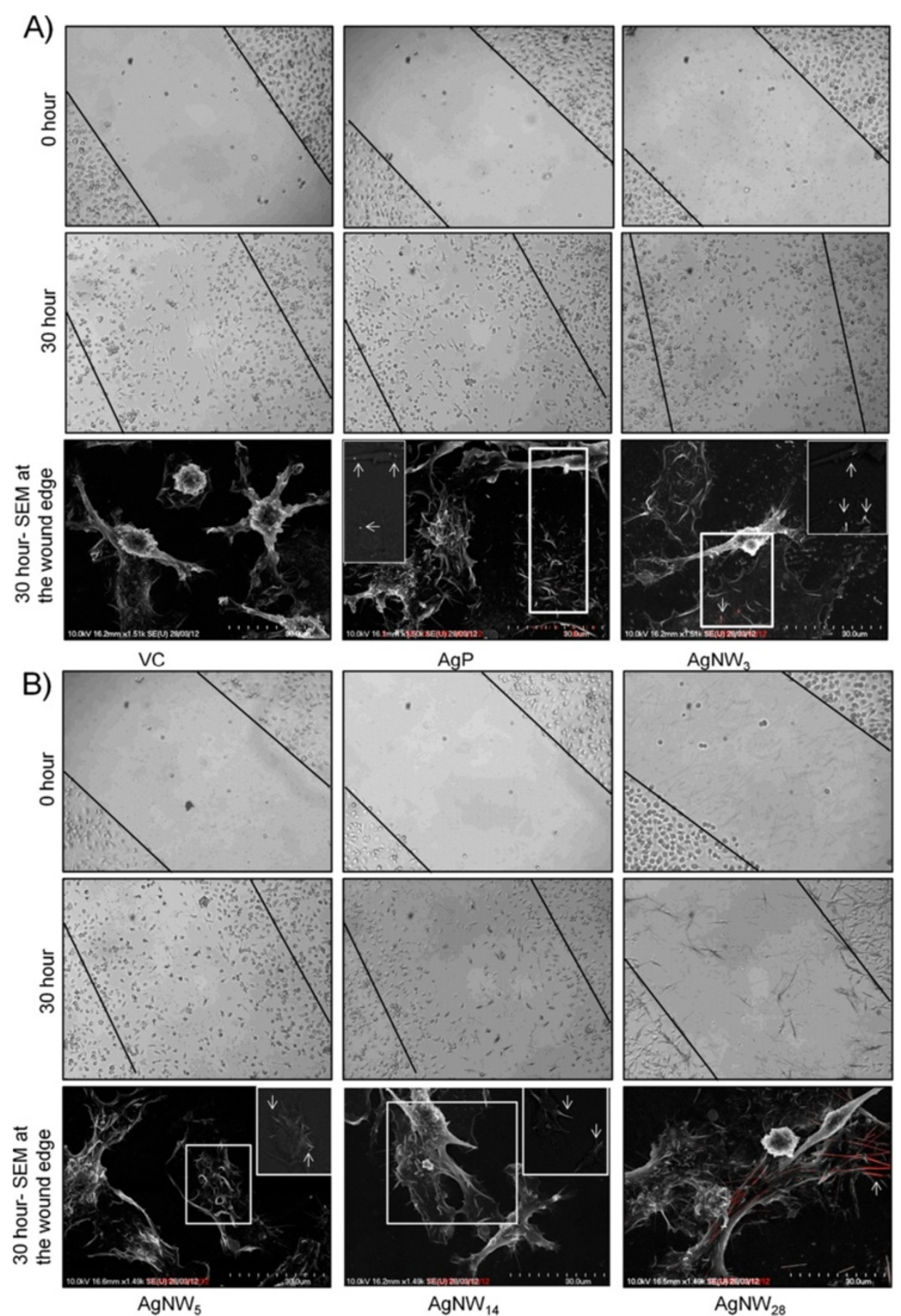

Figure 5 Fibre-length dependent impaired migration of BMMs in a wound-healing assay. A,B) An artificial wound was created in the BMM monolayer using a pipette tip and the migration of BMMs into the wound was assessed after treatment with VC, AgP, AgNW 3 , AgNW 5 , AgNW 14 , $\mathrm{AgNW}_{28}$. The dose was adjusted to fibre number and based on $2.5 \mu \mathrm{g} / \mathrm{cm}^{2}$ for $\mathrm{AgNW}_{14}$. Photographs were taken immediately and at 30 hour after creating the wound. For BSE images were taken at the edge of the wound. No impairment of cell adhesion and spreading could be observed and in fact increased cell spreading due to uptake of longer fibres was observed. Nanoparticles and fibres could be visualised underneath the cell membrane as indicated by the white arrow in the inserts which are the non-overlayed BSE images. Representative images are shown; similar results are obtained in 3 independent experiments. 

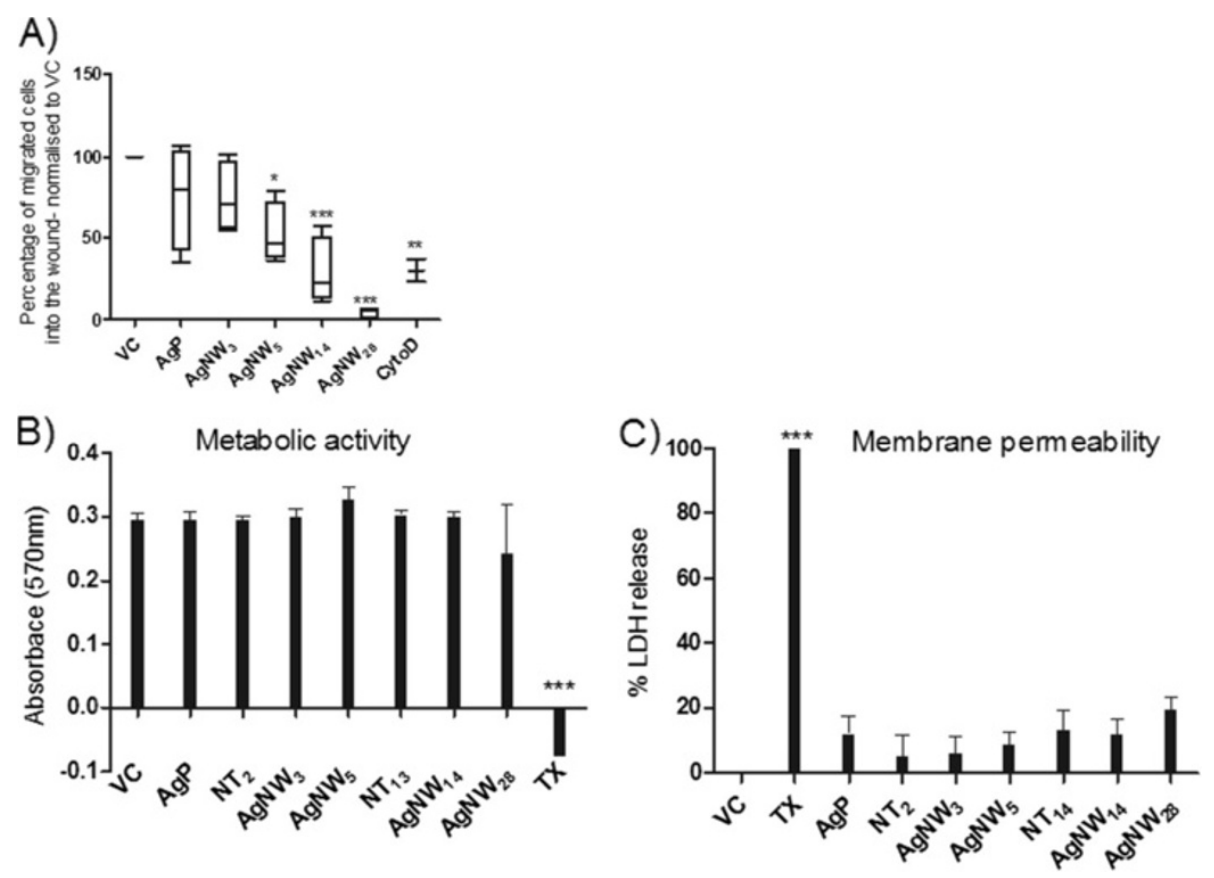

Figure 6 Inhibition of BMMs migration in a wound-healing assay and cell viability. A) The number of cell migrated was counted and expressed as percentage of cells migrated into the wound normalised to VC. Significant reduction of migration was seen with AgNW ${ }_{5}$ AgNW ${ }_{14}$, $\mathrm{AgNW}_{28}$ and cytochalasin D, a positive control for actin cytoskeleton disruption. B) Metabolic activity of BMMs was assessed via the reduction of AlamarBlue ${ }^{\circledR}$ at an absorbance of $570 \mathrm{~nm}$. At the dose used no significant reduction in metabolic activity was measured. C) The integrity of the cell membrane after the different treatments was measured via the release of LDH into the cell supernatant and compared to VC and TX, positive control. A sub-lethal dose was chosen at which none of the treatments lead to a significant increase in cell permeability. Significance indicated compares treatment groups to vehicle control, * indicates $p<0.05$, ${ }^{* *}$ indicates $p<0.001$, ${ }^{* * *}$ indicates $p<0.0001(n=3)$. Data represent mean \pm SEM of $n=3$.

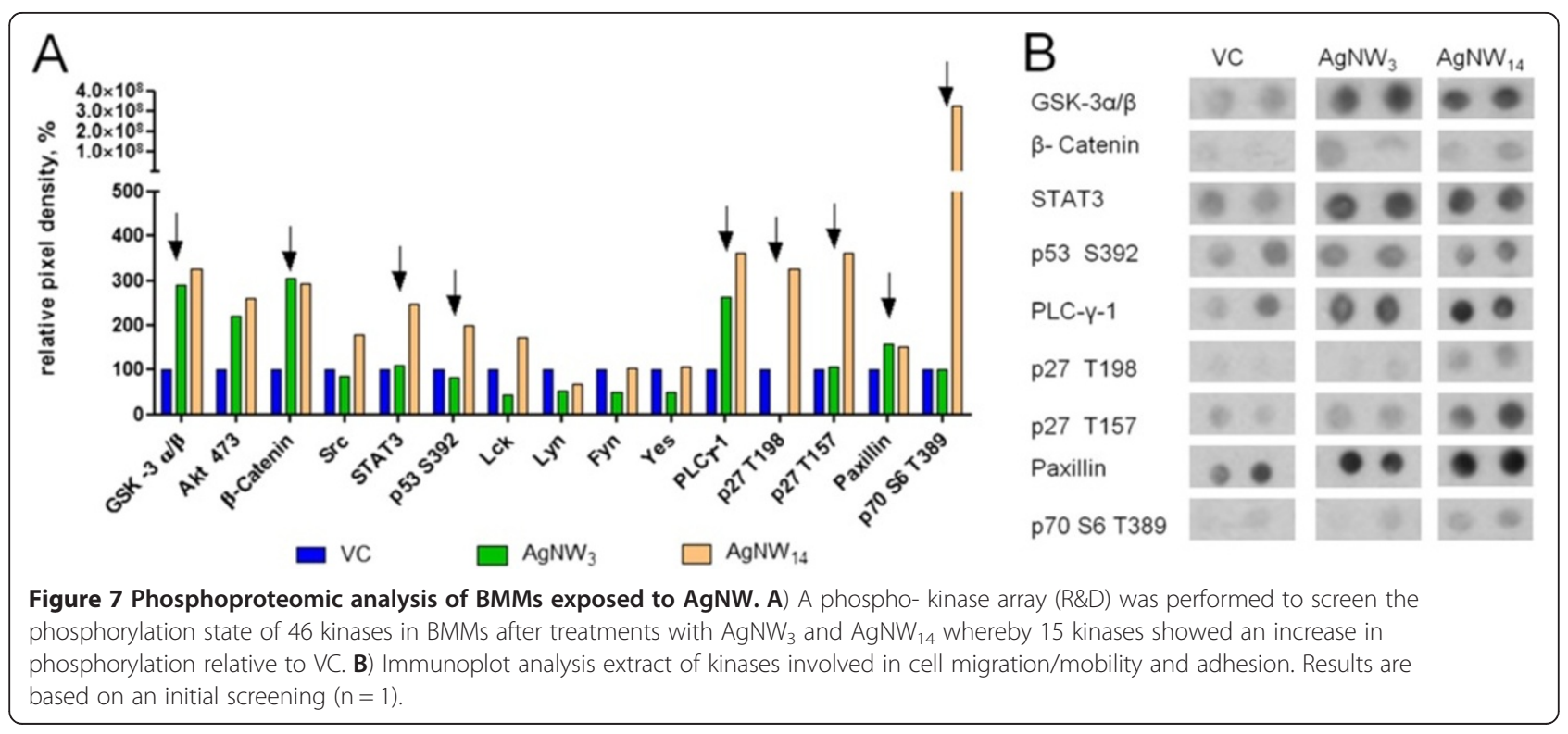




\section{Screening for kinase phosphorylation in BMMs after AgNW treatment}

The phospho- kinase array showed that kinases including GSK-3 $\alpha / \beta$, Akt (S473), $\beta$-catenin and PLC- $\gamma$ were activated on treatment with both the $\mathrm{AgNW}_{3}$ and the $\mathrm{AgNW}_{14}$ which can be explained via a general activation due to phagocytosis of particles (Figure 7A, B). Kinases including STAT3, p53 (S392), p27 (T198), p27 (T157) and p70 S6 (T389) were more activated in $\mathrm{AgNW}_{14}$ compared to $\mathrm{AgNW}_{3}$ which correlate with the loss of locomotion (Figure 7A, B). Interestingly, the highest level of activation of the cytoplasmic tyrosine kinase Src family members including Src, Lck, Hck and Frg was detected in the $\mathrm{AgNW}_{14^{-}}$ treated BMM (Figure 7A, Additional file 1: Table S1). A summary of the relative pixel intensities of all kinases can be found in the Additional file 1: Table S1, Figure S3.

\section{Discussion}

The aim of this study was to investigate lengthdependent effects of AgNW in the lungs. To assess the role of fibre length in the initiation of inflammation the BAL profile was assessed after aspiration exposure. To assess the effect of length on macrophage clearance and retention of the long fibre dose we used an in vitro wound-healing assay. The latter study aimed to shed light onto the effects of fibre length on clearance of fibre-laden alveolar macrophages via migration from the alveolar region of the lung to the mucociliary escalator.

Fibre dimension is a critical factor for lung diseases after inhalation exposure of various forms of fibrous materials as demonstrated in a number of experimental studies, with long fibres being more pathogenic than short ones $[7,8,13,14]$. We recently reported a length threshold of $5 \mu \mathrm{m}$ for inflammation in the pleural cavity using the same range of tightly length -defined silver nanowires used here [9].

Long term inhalation studies in rat have been performed with amosite asbestos preparations of short $(1 \%>5 \mu \mathrm{m})$, medium (UICC reference fibre) and long $(30 \%>5 \mu \mathrm{m}, 11 \%>10 \mu \mathrm{m})$. These studies showed that the short fibres and the slightly longer UICC sample were low in pathogenicity whilst the long fibres induced extensive fibrosis and pulmonary adenomas. This was in contrast to the studies performed using direct injection of the same samples of amosite asbestos into the peritoneal cavity which showed that UICC amosite was sufficiently long to cause mesothelioma in rats at the same frequency as long amosite fibres [8]. This supports findings of the present study, that the length threshold for fibre effects in the lung is different to the length threshold for fibre effects at the mesothelial surface, the lung threshold being a higher value. More recent studies on adverse effects of nanofibres have shown a positive correlation between increasing fibre length and greater lung and pleural/peritoneal inflammation $[4,15,16]$. Poland et al. showed severe lung and peritoneal inflammation after aspiration exposure and direct intraperitoneal injection in mice of long $(24 \mu \mathrm{m})$ nickel nanowire but only very mild diffuse alveolitis and mild peritoneal inflammation after exposure to short $(4 \mu \mathrm{m})$ nickel nanowires [4]. Similar results were obtained from studies on short $(<1 \mu \mathrm{m})$ and long $(>13 \mu \mathrm{m})$ carbon nanotubes where the resultant pathophysiological response was compared to short and long amosite asbestos fibres [15-17]. These studies have shown that carbon nanotubes (CNT) induce a length- dependent inflammation in the peritoneal and pleural space of mice [15-17].

We recently investigated the threshold length for pleural inflammation and reported that various forms of high aspect ratio nanomaterials including amosite asbestos fibres, carbon nanotubes, nickel nanowires and the silver nanowires used here, showed a clear length threshold of $5 \mu \mathrm{m}$ for initiation of an inflammatory response in the pleural space after direct intrapleural injection [9]. The data clearly showed that fibres below $5 \mu \mathrm{m}$ in length were non-inflammatory and that fibres $5 \mu \mathrm{m}$ in length and longer caused extensive recruitment of inflammatory cells $[9,18]$ to the pleural space.

The current study addressed the lack of knowledge regarding the threshold length for acute pulmonary inflammation after deposition in the airspaces of the lungs. The pulmonary response to AgNW reported here showed a threshold length for the significant recruitment of inflammatory cells of $14 \mu \mathrm{m}$ compared to the $5 \mu \mathrm{m}$ fibre threshold length for pleural inflammation $[9,18]$. The use of size categories means that the actual threshold could lie anywhere between 11- and $14 \mu \mathrm{m}$ since the size category below, at which no inflammation was produced was $10 \mu \mathrm{m}$. Our finding of a longer threshold in the lungs is consistent with previous reports implicating longer fibres in the development of lung carcinoma compared to mesothelioma [8,9]. The different length thresholds for pulmonary versus pleural inflammation can be explained as a consequence of the different mechanisms of fibre clearance from the lung and the pleural/ space. Clearance of fibres from the pleural space is via lymphatic drainage to mediastinal lymph nodes through stomata, pores in the parietal pleura which are around $0.5-10 \mu \mathrm{m}$ in diameter [9]. Therefore a sizerestricted clearance occurs in the pleural space leading to a retention of fibres which cannot negotiate the stomata and subsequent recruitment of inflammatory cells [15]. The clearance mechanism in the lung relies on alveolar macrophage phagocytosis and migration to the foot of the mucociliary escalator and is discussed in more detail below. 
While deposition of $\mathrm{AgNW}_{14}$ in the airspaces lead to a significant increase in inflammatory cells in the broncho-alveolar lavage fluid (BAL), shorter fibres including SFA, $\mathrm{AgNW}_{3}, \mathrm{AgNW}_{5}$ and $\mathrm{AgNW}_{10}$ only produced a mild, non significant, increase in the total granulocyte number. It was noticeable that the lengthdependent response was not linear and showed a marked step-increase in the inflammation between 10 and $14 \mu \mathrm{m}$. Histological examination of lung sections showed no recruitment of inflammatory cells after exposure to SFA or $\mathrm{AgNW}_{3}$. Minor aggregations of inflammatory cells around terminal bronchioles and in alveolar airspaces were observed with $\mathrm{AgNW}_{5}$ and $\mathrm{AgNW}_{10}$ but these were more extensive in the $\mathrm{AgNW}_{14}$ and LFA samples showing early stages of granuloma development in the terminal airways/ proximal alveolar region. The histological response to LFA was strongest showing extensive aggregates of inflammatory cells. However, the BAL fluid from LFA-exposed mice, whilst showing an increase in the mean number of granulocyte that was almost 4 times the mean number in the mice exposed to SFA did not attain significance. Additionally, lavage from lungs exposed to LFA resulted in a smaller number of BAL granulocytes than $\mathrm{AgNW}_{14}$ and this contrasted with the histology data that showed more lung inflammation with LFA than AgNW ${ }_{14}$. The low PMN in the lavage from LFA-exposed lungs was possibly due to a poor return from the inflammation-congested areas of the lungs. The final scoring of LFA equal to $\mathrm{AgNW}_{14}$ for BAL granulocytes (Table 2) therefore took into account both the histological and lavage data to provide the best assessment of their relative inflammogenicity. The lack of an inflammatory response with shorter AgNW, which can be considered to be equivalent to silver particles, is consistent with experimental studies demonstrating the minimal lung toxicity or inflammogenicity of nanosilver in a subacute murine and 28-day rat inhalation model
$[19,20]$. The role of silver ion release and its impact on silver nanoparticle toxicity is a controversial topic and experimental situations where soluble silver has been shown to play a role is mainly based on extremely high doses [21]. There is no reason to believe that silver ions played any role here as discussed extensively in our recent paper using the same panel [9] due to the low toxicity of silver nanoparticles and their proclivity to form silver chloride in biological systems. The study presented here focuses on short-time response due to the fact that the AgNW used in this study appear not to be biopersistent beyond a few days [9]. It is highly likely that the same length dependent effects would be shown by wholly biopersistent fibres and that the inflammation would be chronic. However, the determination of the threshold length for long term chronic inhalation studies is of utmost importance and biopersistence remains a key factor in the pathogenicity of long nanofibres.

The clearance efficiency of deposited fibres from the lower respiratory tract plays a major role in the development of pulmonary diseases since the retained dose, which is the dose accumulated in the alveolar region of the lungs after clearance mechanism accounts for the chronic pathogenic effects of inhaled fibres [22].

Fibres deposited in the conducting airways are cleared rapidly via cilia in the mucociliary escalator and subsequently swallowed or expectorated. If fibres reach the respiratory bronchioles, alveolar ducts or alveolar sacs they are cleared slowly via alveolar macrophages (AM) phagocytosing the deposited fibres and transporting them upwards to the ciliated airways for mucociliary clearance. It has been noted in many studies that there is selective retention of long biopersistent fibres of various sorts from the slow-clearing compartment with more effective clearance of the shorter fibres [11,23].

The mechanism by which fibre-laden alveolar macrophages are drawn to the terminal bronchioles at the foot

Table 2 Summary of the length-dependent effects of fibres in the lungs

\begin{tabular}{|c|c|c|c|c|c|c|}
\hline & & \multicolumn{5}{|c|}{ Endpoint } \\
\hline & & $\begin{array}{c}\text { BAL } \\
\text { Granulocytes }\end{array}$ & $\begin{array}{l}\text { Lung } \\
\text { Histology }^{* *}\end{array}$ & $\begin{array}{l}\text { Frustrated } \\
\text { phagocytosis }^{* * * *}\end{array}$ & $\begin{array}{l}\text { Impaired } \\
\text { migration }^{* * * *}\end{array}$ & $\begin{array}{c}\Delta \text { kinase } \\
\text { phosphorylation }^{* * * * *}\end{array}$ \\
\hline \multirow[t]{7}{*}{ Treatment } & Control & + & - & No & - & NA \\
\hline & SFA & + & - & No & NA & NA \\
\hline & LFA & +++ & ++++ & Yes & NA & NA \\
\hline & $\mathrm{AgNW}_{3}$ & + & - & No & - & + \\
\hline & $\mathrm{AgNW}_{5}$ & ++ & + & No & + & + \\
\hline & $\mathrm{AgNW}_{10}$ & ++ & + & No & ++ & NA \\
\hline & $\mathrm{AgNW}_{14}$ & +++ & +++ & Yes & +++ & ++ \\
\hline
\end{tabular}

* BAL granulocytes: <0.5 million (+); 0.5-1.0 million (++); 1-2 million (+++).

** Lung histology subjectively scored on the basis of the severity of lung inflammation (see results).

*** Frustrated phagocytosis on the basis of evaluation of cytospins for presence of frustrated phagocytosis.

**** Impaired migration on the basis of degree of significant impairment compared to control (see Figure 6A).

***** $\Delta$ kinase phosphorylation based on subjective examination the levels of phosphorylation of the treated compared to the control levels of phosphorylation (see Figure 7). $N A=$ not applicable. 
of the ciliated airways is obscure. Possible explanations include the passive transport with alveolar fluid or amoeboid movement of AM either by random migration or directed migration along a chemotactic gradient [24]. Other pathways of clearance, usually only important during high dust exposure or disease are intra- and transcellular pathways by which fibres can reach lung interstitium and lymph nodes from where they subsequently may reach the blood stream $[22,25,26]$. A recent study investigated the effects of MWCNT on cell migration and adhesion of human dermal fibroblasts and murine fibroblasts, reporting a significant decrease in cell adhesion which was confirmed by the decrease of mRNA levels of important cell adhesion proteins FAK, fibronectin and laminin [27]. In addition fibroblast migration in a wound- healing assay was greatly impaired by MWCNT treatment and was accompanied by cytoskeletal derangement [27], although it should be noted that the dose of MWCNT used in this study was cytotoxic to human fibroblast which could influence the adherence and migration properties of the cells.

We set out to investigate whether fibre length has an effect on the migration behaviour of BMMs in vitro after fibre exposure using a wound-healing assay, a surrogate for in vivo clearance of fibrous material to the mucociliary escalator by AM migration. We used a very low dose to study effects on BMM migration, based on $2.5 \mu \mathrm{g} / \mathrm{cm}^{2}$ for $\mathrm{AgNW}_{14}$ and all the other length classes were adjusted to provide the same fibre number. The dose used had no significant effect on cell metabolism or cell viability for any of the length classes, ensuring that the observed effects were not due to simply impaired cell viability. A clear length-dependent trend for inhibition of BMM cell migration was measured at fibre lengths of 5 , 14 and $28 \mu \mathrm{m}$ and at $28 \mu \mathrm{m}$ there was more-or less complete inhibition of motility. Presumably as a consequence of cell surface extension of AM during engulfment of long fibres, increased cell spreading was observed and correlated with increased inhibition of migration. The BMMs in this study had an average diameter of $13 \mu \mathrm{m}$ [28] whilst human alveolar macrophages have an average diameter of $21 \mu \mathrm{m}$ [29]. Due to this difference the threshold length for clearance of fibres by alveolar macrophages in humans may be slightly higher.

An initial screening of 46 kinase phosphorylation sites was performed to get a snapshot of the kinase activation status of fibre- treated BMMs. We hypothesised that this might reveal whether there was any fundamental change in the activation/metabolic state of the cells when they were impaired in their ability to migrate by phagocytosing long fibres. The $3 \mu \mathrm{m}$ long exposed cells act as a control for normal phagocytosis and when compared to the untreated kinase profile this showed most of the kinases ( 32) remained unchanged. The kinases GSK-3 $\alpha / \beta$, Akt 473, $\beta$-catenin and PLC- $\gamma$ showed activation in all treatment groups suggesting a link to normal phagocytosis. Comparing the kinase phosphorylation profile of $\mathrm{BMM}$ exposed to $3 \mu \mathrm{m}$ with those exposed to $14 \mu \mathrm{m}$ should reveal differences associated with the long fibredependent loss of motility and 5 kinases out of 46 (STAT3, p53 (S392), p27 (T198), p27 (T157) and p70 S6 (T389)) exhibited increased phosporylation with $\mathrm{AgNW}_{14}$ compared to $\mathrm{AgNW}_{3}$. Tyrosine kinases of the Src family were noticeably induced by treatment with long fibres. These kinases have been implicated in intracellular signalling in macrophages influencing the amplitude of many pathways [30]. One of the Src downstream effectors is STAT3, a major modulator of inflammation, which is required for activation of macrophages [31]. A marked Induction of STAT3 following the $\mathrm{AgNW}_{14}$ treatment is a likely result of Src activation. It's worth mentioning that a constitutive activation of STAT3 is a common feature in many solid tumours [32], therefore persisting activation of STAT3 in a chronic inflammation caused by long fibres may contribute to pro-oncogenic changes. Macrophage motility is known to be negatively regulated by p53 [33] and the latter was induced in BMM treated with longer fibres, and might have contributed to impairment of their migration. The role of p27 in regulation of cellular migration remains unclear, however, our finding would support the reports showing suppression of migration by induction of p27 [34]. No kinases were down-regulated in the long fibre treated BMM compared to the controls confirming that there was no generalised loss of viability associated with failure to migrate. It is reported in the literature that a number of different kinase pathways are involved in the migration and adhesion processes among these are kinases that showed an increase in their phosphorylation state after long fibre treatment [35-41]. The results from the screening of the phosphorylation sites was mainly performed to see if crucial cellular signalling processes are impaired by the treatment of AgNW which might indicate that decreased cellular function, apoptosis/necrosis underlay the decrease in cell mobility. Our results showed that the long-fibre treatment did not negatively affect the cellular function of the BMMs as assessed by metabolic function, loss of membrane integrity or kinase profile. In fact long fibre treatment and inhibition of motility were associated with increased phosphorylation of some kinases involved in migration and adhesion. Clearly the interplay between adhesion and motility is complex since focal adhesion is required for motility and a more sophisticated analysis of mechanism underlying loss of motility with long fiber treatment is required but is outwith the scope of the present paper. The results give an indication that cellular processes are intact in long fiber treated BMM and therefore that inhibition of locomotion 
can be best explained via a mechanical obstruction to motility. By this we suggest that the presence of long fibres inside the cells physically interferes with the necessary rearrangement of the cytoskeleton, membrane and other structures that are necessary for locomotion. This however has to be confirmed by an in depth investigation of the molecular mechanism involved in inhibition of migration which is beyond the scope of the present manuscript.

\section{Conclusion}

In conclusion we have shown that there are lengthdependent effects on the lung and on BMM summarised in Table 2. These show length-dependent increases in inflammation by BAL and severity of lung injury by histology in vivo and evidence of accompanying impairment of macrophage migration by BMM in vitro; frustrated phagocytosis was only evident at the longest fibre lengths indicating that complete uptake of longer fibres still causes cell impairment, in the absence of classical frustrated phagocytosis as we previously reported $[9,12]$. A threshold length for acute pulmonary inflammation after pharyngeal aspiration of AgNW was evident between 10 and $14 \mu \mathrm{m}$ in length. This compares with our previous studies on the threshold length for pleural inflammation of $5 \mu \mathrm{m}$, determined using a panel that utilised the AgNW used here [9]. No previous study has used tight length- restricted fibre populations to demonstrate thresholds as shown here and in our previous study in the pleural space [9]. The present study showing that the threshold length for induction of pulmonary inflammation is longer than the threshold length for pleura inflammation is in accordance with extrapolations using asbestos fibres [8]. The difference in thresholds can be explained by the differences in clearance mechanism between the lung the pleural space. In the pleural space clearance is through stomata [6] whilst clearance of deposited fibres from beyond the ciliated airways is via uptake by $A M$ and subsequent migration to the mucociliary escalator. Using an in vitro wound healing assay we showed that fibre length-dependent macrophage mobility, with a threshold for impairment at a length of $5 \mu \mathrm{m}$ and increasing impairment with increasing length, until at $28 \mu \mathrm{m}$ there was almost complete inhibition of motility. An explanation for the decrease in locomotion could be mechanical obstruction caused simply by the bulky long fibres interfering with the movement process since there was no loss of viability or respiration in the long fibre-treated cells and an initial screen of a number of 46 kinases showed no decrease kinase phosphorylations. We note however that this is a small-scale aspiration study with acute inflammation and short term inhibition of migration in vitro as the endpoints. Our results need to be confirmed in long term inhalation studies using a range of different nanofibres at plausible exposure before we can confidently utilize these thresholds for risk assessment and in benign-by-design for nanofibres.

\section{Methods \\ Particle panel}

The panel of particles investigated here consisted of four silver nanowires (AgNW) samples (Figure 1), a silver nanoparticle control (AgP) and two amosite asbestos samples, long amosite asbestos (LFA) and short amosite asbestos (SFA) as previously described in Schinwald et al. [9]. AgP was purchased from Nanostructured \& Amorphous Materials, Inc. with a diameter of $35 \mathrm{~nm}$, a purity of $99,5 \%$ and a specific surface area of $30-50 \mathrm{~m}^{2} / \mathrm{g}$. The AgNW samples were kindly provided by Seashell Technology, San Diego (www.seashelltech.com). The polyol process was used for the synthesis of the AgNW which is described in patent number 7,922,787 B2. Detailed description of particle panel characteristics including concentration of soluble metal and dissolution can be found in Schinwald et al. [9]. AgNW synthesis and reaction conditions to obtain different lengths did not affect the chemical composition of the different nanowires and no coating of the nanowires was performed. The panel was dispersed in isopropanol and diluted to a working concentration of $1 \mathrm{mg} / \mathrm{ml}$ in $0.5 \%$ bovine serum albumin (BSA; Sigma-Aldrich, Poole, UK)/ saline. For light microscope images the AgNW (1 mg/ $\mathrm{ml}$ ) were were mixed with $10 \mu \mathrm{l}$ of glycerol (SigmaAldrich, Poole, UK) to reduce the flow of AgNW. The suspension was placed on glass slide and covered with a glass coverslip and sealed [15]. Images were captured at x40 magnification using QCapture Pro software (Media Cybernetics). As a control panel mixed length amosite asbestos enriched for long fibres (100\% fibres $\geq 5 \mu \mathrm{m}$, $50.3 \%$ fibres $>15 \mu \mathrm{m}, 35.2 \%$ fibres $>20 \mu \mathrm{m}$ ), hereafter referred to as long fibre asbestos (LFA), and shortened amosite asbestos (SFA; 3.1\% fibres $\geq 5 \mu \mathrm{m}$, mean length $1 \mu \mathrm{m}$, mean diameter $300 \mathrm{~nm}$ ) [42] were used.

\section{In vivo}

\section{Experimental animals}

Nine week old female C57BL/6 strain mice (Harlan, UK) were used in this study. Mice were kept in a group size of five in standard caging with sawdust bedding within a pathogen-free Home Office approved facility. Mice were maintained on a normal 12 hour light and dark cycle. Prior to the treatment mice were kept for 7 days in the facility to acclimatise. The work was carried out by staff holding a valid UK Home Office personal licence under a Home Office approved project licence. 


\section{Pharyngeal aspiration and bronchoalveolar lavage}

The dose of AgNW panel for pharyngeal aspiration was equalised to fibre number since fibre exposure is regulated on the basis of the fibre number and so relative potency needs to be determined on a per-fibre basis. To equalise for fibre number a dose of $50 \mu \mathrm{g} /$ mouse for $\mathrm{AgNW}_{14}$ was chosen as the standard in vivo dose based on previous measurement of membrane integrity and proliferation. Based on $50 \mu \mathrm{g} / \mathrm{mouse}$ for $\mathrm{AgNW}_{14}$, concentrations for the other length classes AgNW panel were calculated assuming that fibres thickness was constant in the different length classes (Table 1). Particle panel was dispersed in $0.5 \%$ bovine serum albumin (BSA; Sigma-Aldrich, Poole, U.K.)/saline and briefly vortexed to assist dispersion. Vehicle control (VC) consisted of $0.5 \% \mathrm{BSA} /$ saline.

Mice were anesthetized with isoflurane (2-chloro-2(difluoromethoxy)-1,1,1 trifluoroethane) and the tongue was gently held in full extension while $50 \mu \mathrm{l}$ of particle suspension was pipette onto the base of the tongue [43]. The tongue was held extended until at least two breaths were complete. To stimulate inhalation and to induce a gasp reflex the nasal cavities of the mice were covered. Mice were observed until full recovery.

Mice were sacrificed at 24 hour by terminal anaesthesia. $0.5 \mathrm{ml}$ of pentobarbitone $(200 \mathrm{mg} / \mathrm{ml})(2,2,2$-Tribromomethanol) was injected in the peritoneal cavity followed by exsanguinations via the abdominal aorta. The thoracic cavity was exposed and the trachea cannulated using a 23 gauge needle and legated. The lungs were lavaged three times with $800 \mu$ l of ice-cold sterile saline. The first lavage was retained separately for LDH and total protein measurements and the subsequent lavages were pooled.

Calculation for total fibre number: e.g. $\mathrm{AgNW}_{3}$

Length of NW (average) $[\mu \mathrm{m}]=3.00$

Diameter of NW $[\mu \mathrm{m}]=0.115$

Density of NW $[\mu \mathrm{g} / \mathrm{ml}]=1.05 \times 10^{-7}$

$$
\begin{aligned}
\text { Volume of } \mathrm{NW}[\mathrm{ml}] & =3 * \prod *\left(\frac{0.115}{2}\right)^{2} \\
& =0.03116 \times 10^{-14} \\
\text { Weight of } \mathrm{NW}[\mu \mathrm{g}] & =3.116 \times 10^{-14} \times 1.05 \times 10^{-7} \\
& =3.272 \times 10^{-7}
\end{aligned}
$$

Dose $[\mu \mathrm{g}]$ per mouse $=10.70$

$$
\begin{aligned}
\text { Number of NW } & =\frac{10.70}{3.272 \times 10^{-7}} \\
& =32719592.52 \cong 32.71 \times 106 \text { fibers }
\end{aligned}
$$

\section{Lung dissection}

For histological examination of lung pathology no forgoing BAL was performed and $\mathrm{n}=2$ for each treatment was used. $10 \%$ formalin was instilled into the lungs to fix the lung tissue and removed 'en block' with the heart. The lung and heart were kept for 4 hours in fixative prior to processing. The heart was removed and the lung was dissected into individual lobes and placed flat in a tissue cassette. The tissue was dehydrated through graded alcohol (ethanol) and embedded in paraffin. $4 \mu \mathrm{m}$ sections were cut from the block covering all lobes of the lung and stained with $\mathrm{H} \& \mathrm{E}$ to show gross pathology.

\section{Differential cell count/ total protein and lactate dehydrogenase measurement}

The cellular fraction was separated from the supernatant of lavage fluid from BAL by centrifugation for 5 minutes at $2000 \mathrm{~g}$ at $4^{\circ} \mathrm{C}$ in a Mistral $3000 \mathrm{i}$ centrifuge (Thermo Fisher Scientific, Inc., MA, USA). Total cell count was performed using a NucleoCounter (ChemoMetec, $7 \mathrm{~A} / \mathrm{S}$, Allerød, Denmark) and cyto-centrifugation with following Diff-Quik staining using Diff-Quik stainset (Dade Behring Gmbh, Marburg, Germany) were prepared for differential cell counts.

In the supernatant, membrane integrity using the Cytotoxicity Detection Lactate Dehydrogenase kit (Roche 25 Diagnostics Ltd., Burgess Hill, UK) and protein content using the bicinchoninic acid (BCA) protein assay (Sigma-Aldrich, Poole, UK) were measured following the manufacturer's instructions.

\section{In vitro}

\section{Generation of bone marrow derived macrophages}

Bone marrow-derived macrophages (BMMs) were generated from 8 week old wild-type C57/B16 mouse femurs and tibias. In brief, the bone marrow was flushed with PBS using a 24 gauge needle, resuspended, passed through a cell strainer and centrifuged at $15000 \mathrm{rpm}$ for $3 \mathrm{~min}$. Cells were resuspended in red blood cell lysis buffer Hybrid Max ${ }^{\text {TM }}$ (Sigma- Aldrich, UK) for 5 min at room temperature. Cells were centrifuged, resuspended in DMEM (Dulbecco's Modified Eagle Medium, Life Technologies) containing 10\% FCS, 1\% penicillin/ streptomycin and 20\% L929 cell media and plated in a $10-\mathrm{cm}^{2}$ non tissue coated dish and cultured for 7 days.

\section{Wound healing assay}

After 7 day differentiation BMMs were seeded in 24 well plates at a density of $0.5 \times 10^{6} / \mathrm{ml}$ in DMEM containing $10 \%$ FCS, $1 \%$ penicillin/ streptomycin and $20 \%$ L929 cell media and culture for 2 days as a confluent monolayer. The medium was replaced with DMEM containing 0\% FCS and 1\% penicillin/ streptomycin. Cells were treated with AgNW equalised to fibre number. To equalise for fibre number a dose of $2.5 \mu \mathrm{g} / \mathrm{cm}^{2}$ for $\mathrm{AgNW}_{14}$ was chosen as the standard in vitro dose based on previous measurement of membrane integrity and proliferation. 
Based on $2.5 \mu \mathrm{g} / \mathrm{cm}^{2}$ for $\mathrm{AgNW}_{14}$, concentrations for the other length classes AgNW panel were calculated assuming that fibres thickness was constant in the different length classes (Table 3). For the control particle, AgP, a dose of $0.5 \mu \mathrm{g} / \mathrm{cm}^{2}$ was used, equal to the shortest fibre $\left(\mathrm{AgNW}_{3}\right)$. The panel was dispersed in $0.5 \% \mathrm{BSA} /$ cell culture medium (DMEM, 0\% FCS) and added to the cells. An artificial wound was created by scraping with a pipette tip and the number of cells migrating into the wound was monitored microscopically and photographs were taken immediately and after 30 hour. Images were acquired through a Zeiss Axiovert S100 microscope equipped with a 30x objective lens and were captured using RS Photometrics CoolSnap. The number of cells migrated into the wound was counted and expressed as percentage compared to vehicle control. Results are given as the mean \pm SEM of 3 independent experiments.

\section{Backscatter scanning electron microscopy}

Backscatter scanning electron microscopy is based on elastic scattering of high energy electron further inside the sample. Elements with high atomic numbers $(Z)$ such as silver give a stronger signal then lower $\mathrm{Z}$ elements. The signal is in general weak and can therefore only provide a contrast between regions with a larger difference in atomic number [12].

BMM cells were prepared as described above and seeded into 24 well plates on ThermanoxR Plastic Coverslips (NUNC ${ }^{\mathrm{TM}}$, Rochester, NY USA) at a density of $0.5 * 10^{6} / \mathrm{ml}$. The cells were treated for 30 hours using concentration as described above at $37^{\circ} \mathrm{C}$ in $5 \% \mathrm{CO} 2$ atmosphere. After the treatment they were washed $5 \mathrm{x}$ with $0.1 \mathrm{M}$ sodium cacodylate ( $\mathrm{pH}$ 7.2) buffer. Cells were fixed overnight in 3\% glutaraldehyde/ $0.1 \mathrm{M}$ sodium cacodylate $(\mathrm{pH}$ 7.2) buffer and subsequently washed three times in sodium cacodylate buffer.

BSE of carbon-coated specimens was carried out using a Hitachi 4700 II field emission SEM (Hitachi HighTech, Maidenhead, UK) at a beam accelerating voltage of $10 \mathrm{kV}$ and a working distance of about $8 \mathrm{~mm}$. Secondary electron (SE) and BSE images were taken simultaneously using an annular YAG crystal BSE detector and the upper SE detector to produce perfectly-synchronised image pairs. Both images were superimposed using

Table 3 Calculation for the mass adjustments for equalisation of fibre number in vitro

\begin{tabular}{|c|c|c|c|}
\hline $\begin{array}{l}\text { Length class } \\
{[\mu \mathrm{m}]}\end{array}$ & $\begin{array}{l}\text { Calculation to equalise for } \\
\text { the same fibre number }\end{array}$ & $\begin{array}{l}\text { Dose } \\
\left(\mu \mathrm{g} / \mathrm{cm}^{2}\right)\end{array}$ & $\begin{array}{l}\text { Total fibre } \\
\text { number }\end{array}$ \\
\hline 3 & $3 / 14 \times 2.5$ & 0.5 & 1528953 \\
\hline 5 & $5 / 14 \times 2.5$ & 0.9 & 1568374 \\
\hline 14 & standard & 2.5 & 1638164 \\
\hline 28 & $28 / 14 \times 2.5$ & 5 & 1638164 \\
\hline
\end{tabular}

Adobe Photoshop. The SE and BSE image were converted to grayscale, the BSE image was pasted into the SE image by using the layer function "lighten". This newly merged image and the SE image were converted to RGB mode, and overlayed by pasting the red channel of the BSE image into the red channel of the greyscale SE image, thus colour coding in red the strong BSE signal from the nanowires, the SE image appearing in grey.

\section{Measurement of membrane integrity and proliferation of BMMs}

Supernatant of the wound healing assay was collected and analysed for membrane integrity using using the Cytotoxicity Detection Lactate Dehydrogenase kit (Roche Diagnostics Ltd., Burgess Hill, UK) following the manufacturer's instructions. TritonX (Sigma) was used as a positive control for cell death and was added at a final concentration of $0.1 \%$ for 30 mins. The supernatant was centrifuged for 5 mins at $2000 \mathrm{rpm}$, transferred and centrifuged again for 5 mins at $13000 \mathrm{rpm}$. The conversion of lactate to pyruvate was detected using a microplate reader $\left(\right.$ BioTek $^{\circledR}$ SynergyHT) to measure the optical density at $490 \mathrm{~nm}$. Results are given as the mean \pm SEM of 3 independent experiments.

Cells in the culture dish were used to measure their proliferation and metabolic activity via a chemical reduction of AlamarBlue $^{\circledR}$ (Invitrogen). $150 \mu \mathrm{l}$ of PBS and $15 \mu \mathrm{l}$ of AlamarBlue $^{\circledR}$ was added to each well and incubated for 3 hours at $37^{\circ} \mathrm{C}$ in $5 \% \mathrm{CO} 2$ atmosphere. Absorbance was monitored at $570 \mathrm{~nm}$ and $600 \mathrm{~nm}$ as a reference wavelength. Data are normalized to $600 \mathrm{~nm}$ value. Results are given as the mean \pm SEM of 3 independent experiments.

\section{Proteome profiler array}

BMMs were differentiated as described above and seeded at $0.5 \times 10^{6} / \mathrm{ml}$ in DMEM containing $10 \%$ FCS, $1 \%$ penicillin/ streptomycin and 20\% L929 cell media and culture for 2 days as a confluent monolayer in a $60 \mathrm{~mm}$ tissue culture dish. The medium was replaced with DMEM containing $0 \%$ FCS and 1\% penicillin/streptomycin and the particle panel was added at the concentrations described above and treated for $30 \mathrm{~h}$. The cells were rinsed with cold phosphate-buffered saline (PBS) and immediately solubilised in lysis buffer by pippeting up and down and rocking the cell lysate at $4^{\circ} \mathrm{C}$ for $30 \mathrm{~min}$. The lysate was centrifuged at $14,000 \times \mathrm{g}$ for $5 \mathrm{~min}$, the supernatant was transferred into new test tubes and the protein concentration was measured using the bicinchoninic acid (BCA) protein assay (Sigma-Aldrich, Poole, UK) following the manufacturer's instructions. $500 \mu \mathrm{g}$ of lysates were diluted and incubated with the HumanPhospho - MAPK Array Kit (Proteome Profiler ${ }^{\mathrm{TM}}$, R\&D Systems) as per manufacturer's instructions. Plots were 
developed on X-ray films following exposure to chemiluminescent reagents.

\section{Statistical analysis}

All data are shown as the mean \pm s.e.m. and these were analysed using one-way analysis of variance (ANOVA). Multiple comparison were analysed using Tukey-HSD method and in all cases, values of $\mathrm{P}<0.05$ were consider significant. (GraphPad InStat Software Inc., CA, USA).

\section{Additional file}

Additional file 1: Figure S1. 24 hour wound healing assay in BMMs. SEM images showing the closer of the wound after 24 hour at different treatments with AgNW. Table S1: Phosphoproteomic analysis of BMMs exposed to AgNW. A phospho- kinase array (R\&D) was performed to screen the phosphorylation state of 46 kinases in BMMs after treatments with AgNW. Relative pixel density in \% compared to VC is shown for all kinases measured $(n=1)$. Figure $\mathbf{S 2}$ : Phospho-kinase array immunoplots. A) VC, B) AgNW3, C)AgNW5, D) AgNW14.

\section{Abbreviations}

BSE: Backscatter scanning electron microscopy; BMM: Bone marrow derived macrophages; FPP: Fibre pathogenicity paradigm; LDH: Lactate deydrogenase; LFA: Long fibre amosite asbestos; SEM: Scanning electron microscopy; SFA: Short fibre amosite asbestos; AgNW: Silver nanowire; AgP: Silver nanoparticle; VC: Vehicle control.

\section{Competing interests}

The authors declare that they have no competing interests.

\section{Authors' contributions}

AS conceived and designed the experiments, analysed the data and wrote the manuscript. KD initiated the study, oversaw all experimental work and contributed to manuscript preparation. TC performed the proteome kinase array and contributed to the manuscript preparation. All authors read and approved the final manuscript.

\section{Acknowledgements}

We thank S. Mitchell (University of Edinburgh) for sample preparation for SEM and technical assistance. We also thank James R. Glass, Janet C. Dickerson and David A. Schultz from Seashell Technology for providing the AgNW samples. This research was funded by the Colt Foundation (A.S., K.D.) and MRC (T.C)

\section{Author details}

'MRC/University of Edinburgh, Centre for Inflammation Research, Queen's Medical Research Institute, 47 Little France Crescent, Edinburgh EH16 4TJ, UK. ${ }^{2}$ MRC Toxicology Unit, Hodgkin Building, Lancaster Road, Leicester LE1 9HN, UK.

Received: 17 October 2012 Accepted: 26 November 2012

Published: 2 December 2012

\section{References}

1. Donaldson K: The inhalation toxicology of p-aramid fibrils. Crit Rev Toxicol 2009, 39:487-500.

2. Mossman BT, Lippmann M, Hesterberg TW, Kelsey KT, Barchowsky A, Bonner JC: Pulmonary endpoints (lung carcinomas and asbestosis) following inhalation exposure to asbestos. J Toxicol Environ Health B Crit Rev 2011, $14: 76-121$.

3. Oberdorster $\mathrm{G}$ : Determinants of the pathogenicity of man-made vitreous fibers (MMVF). Int Arch Occup Environ Health 2000, 73(Suppl:S60-8):S60-S68.

4. Poland CA, Byrne F, Cho WS, Prina-Mello A, Murphy FA, Davies GL, et al: Length-dependent pathogenic effects of nickel nanowires in the lungs and the peritoneal cavity. Nanotoxicology 2011, 6:899-911.
5. Mercer RR, Hubbs AF, Scabilloni JF, Wang L, Battelli LA, Friend S, et al: Pulmonary fibrotic response to aspiration of multi-walled carbon nanotubes. Part Fibre Toxicol 2011, 8:21.

6. Donaldson K, Murphy FA, Duffin R, Poland CA: Asbestos, carbon nanotubes and the pleural mesothelium: a review of the hypothesis regarding the role of long fibre retention in the parietal pleura, inflammation and mesothelioma. Part Fibre Toxicol 2010, 7(5):5.

7. Davis JM, Beckett ST, Bolton RE, Collings P, Middleton AP: Mass and number of fibres in the pathogenesis of asbestos-related lung disease in rats. Br J Cancer 1987, 37:673-688.

8. Davis JM, Addison J, Bolton RE, Donaldson K, Jones AD, Smith T: The pathogenicity of long versus short fibre samples of amosite asbestos administered to rats by inhalation and intraperitoneal injection. Br J Exp Pathol 1986, 67:415-430.

9. Schinwald A, Murphy FA, Prina-Mello A, Poland CA, Byrne F, Movia D, et al: The threshold length for fiber-induced acute pleural inflammation: shedding light on the early events in asbestos-induced mesothelioma. Toxicol Sci 2012, 128:461-470.

10. Coin PG, Osornio-Vargas AR, Roggli VL, Brody AR: Pulmonary fibrogenesis after three consecutive inhalation exposures to chrysotile asbestos. Am J Respir Crit Care Med 1996, 154:1511-1519.

11. Searl A, Buchanan D, Cullen RT, Jones AD, Miller BG, Soutar CA: Biopersistence and durability of nine mineral fibre types in rat lungs over 12 months. Ann Occup Hyg 1999, 43:143-153.

12. Schinwald A, Donaldson K: Use of back-scatter electron signals to visualise cell/nanowires interactions in vitro and in vivo; frustrated phagocytosis of long fibres in macrophages and compartmentalisation in mesothelial cells in vivo. Part Fibre Toxicol 2012, 9:34.

13. Stanton MF, Layard M, Tegeris A, Miller E, May M, Morgan E, et al: Relation of particle dimension to carcinogenicity in amphibole asbestoses and other fibrous minerals. JNCl 1981, 67:965-975

14. Vorwald AJ, Durkan TM, Pratt PC: Experimental studies of asbestosis. AMA Arch Ind Hyg Occup Med 1951, 3:1-43.

15. Murphy FA, Poland CA, Duffin R, Al-Jamal KT, Ali-Boucetta H, Nunes A, et al Length-dependent retention of carbon nanotubes in the pleural space of mice initiates sustained inflammation and progressive fibrosis on the parietal pleura. Am J Pathol 2011, 178:2587-2600.

16. Murphy FA, Poland CA, Duffin R, Donaldson K: Length-dependent pleural inflammation and parietal pleural responses after deposition of carbon nanotubes in the pulmonary airspaces of mice. Nanotoxicology 2012, 6:2587-2600.

17. Poland CA, Duffin R, Kinloch I, Maynard A, Wallace WA, Seaton A, et al: Carbon nanotubes introduced into the abdominal cavity of mice show asbestos-like pathogenicity in a pilot study. Nat Nanotechnol 2008, 3:423-428.

18. Schinwald A, Murphy F, Prina-Mello A, Poland CA, Byrne F, Glass JR, et al The threshold length for fibre-induced acute pleural inflammation: shedding light on the early events in asbestos-induced mesothelioma. Toxicol Sci, . in press.

19. Stebounova LV, mcakova-Dodd A, Kim JS, Park H, O'Shaughnessy PT, Grassian VH, et al: Nanosilver induces minimal lung toxicity or inflammation in a subacute murine inhalation model. Part Fibre Toxicol 2011, 8:5.

20. Ji JH, Jung JH, Kim SS, Yoon JU, Park JD, Choi BS, et al: Twenty-eight-day inhalation toxicity study of silver nanoparticles in Sprague-Dawley rats Inhal Toxicol 2007, 19:857-871.

21. Johnston HJ, Hutchison G, Christensen FM, Peters S, Hankin S, Stone V: A review of the in vivo and in vitro toxicity of silver and gold particulates: particle attributes and biological mechanisms responsible for the observed toxicity. Crit Rev Toxicol 2010, 40:328-346.

22. Oberdorster G: Lung dosimetry: pulmonary clearance of inhaled particles. Aerosol Sci Tech 1993, 18:279-289.

23. Lippmann M: Effects of fiber characteristics on lung deposition, retention, and disease. Environ Health Perspect 1990, 88:311-317.

24. Lehnert BE: Pulmonary and thoracic macrophage subpopulations and clearance of particles from the lung. Environ Health Perspect 1992, 97:17-46.

25. Holt PF: Translocation of inhaled dust to the pleura. Environ Res 1983, 31:212-220

26. Miserocchi G, Sancini G, Mantegazza F, Chiappino G: Translocation pathways for inhaled asbestos fibers. Environ Health 2008, 7:4. 
27. Zhang Y, Wang B, Meng X, Sun G, Gao C: Influences of acid-treated multiwalled carbon nanotubes on fibroblasts: proliferation, adhesion, migration, and wound healing. Ann Biomed Eng 2011, 39:414-426.

28. Cannon GJ, Swanson JA: The macrophage capacity for phagocytosis. J Cell Sci 1992, 101:907-913.

29. Krombach F, Munzing S, Allmeling AM, Gerlach JT, Behr J, Dorger M: Cell size of alveolar macrophages: an interspecies comparison. Environ Health Perspect 1997, 105:1261-1263.

30. Abram CL, Lowell CA: The diverse functions of Src family kinases in macrophages. Front Biosci 2008, 13:4426-4450.

31. Lin T, Bost KL: STAT3 activation in macrophages following infection with Salmonella. Biochem Biophys Res Commun 2004, 321:828-834.

32. Looyenga BD, Hutchings D, Cherni I, Kingsley C, Weiss GJ, Mackeigan JP. STAT3 Is Activated by JAK2 Independent of Key Oncogenic Driver Mutations in Non-Small Cell Lung Carcinoma. PLoS One 2012, 7.

33. Sablina AA, Chumakov PM, Kopnin BP: Tumor suppressor p53 and its homologue p73 alpha affect cell migration. J Biol Chem 2003, 278:27362-27371.

34. Berton S, Belletti B, Wolf K, Canzonieri V, Lovat F, Vecchione A, et al: The tumor suppressor functions of p27(kip1) include control of the mesenchymal/amoeboid transition. Mol Cell Biol 2009, 29:5031-5045.

35. Kobayashi T, Hino S, Oue N, Asahara T, Zollo M, Yasui W, et al: Glycogen synthase kinase 3 and h-prune regulate cell migration by modulating focal adhesions. Mol Cell Biol 2006, 26:898-911.

36. Ip CK, Wong AS: p70 S6 kinase and actin dynamics: a perspective. Spermatogenesis 2012, 2:44-52.

37. Roger $L$, Gadea G, Roux P: Control of cell migration: a tumour suppressor function for p53? Biol Cell 2006, 98:141-152

38. Huang C, Rajfur Z, Borchers C, Schaller MD, Jacobson K: JNK phosphorylates paxillin and regulates cell migration. Nature 2003, 424:219-223.

39. Lee MH, Koria P, Qu J, Andreadis ST: JNK phosphorylates beta-catenin and regulates adherens junctions. FASEB J 2009, 23:3874-3883.

40. Yoon JH, Kim HE, Choi JY, Bae HJ, Lee SG: Caffeoylserotonin suppresses THP-1 monocyte adhesion and migration via inhibition of the integrin beta1/FAK/Akt signalling pathway. Fitoterapia 2012.

41. Baruzzi A, Caveggion E, Berton G: Regulation of phagocyte migration and recruitment by Src-family kinases. Cell Mol Life Sci 2008, 65:2175-2190.

42. Donaldson K, Brown GM, Brown DM, Bolton RE, Davis JG: Inflammation generating potential of long and short fiber amosite asbestos samples. Br J Ind Med British 1989, 46:271-276.

43. Rao GV, Tinkle S, Weissman DN, Antonini JM, Kashon ML, Salmen R, et al: Efficacy of a technique for exposing the mouse lung to particles aspirated from the pharynx. J Toxicol Environ Health A 2003, 66:1441-1452.

\section{Submit your next manuscript to BioMed Central and take full advantage of:}

- Convenient online submission

- Thorough peer review

- No space constraints or color figure charges

- Immediate publication on acceptance

- Inclusion in PubMed, CAS, Scopus and Google Scholar

- Research which is freely available for redistribution

Submit your manuscript at www.biomedcentral.com/submit 